\title{
Indicadores de gestión comunitaria: aportes desde la mirada de las personas directoras de instituciones educativas
}

\section{Community management indicators: contributions from the perspective of the headteachers of educational institutions}

\section{Indicadores de gestão comunitária: contribuições do ponto de vista dos diretores das escolas}

\author{
Adrián Solano Castro \\ Universidad Estatal a Distancia \\ San José, Costa Rica \\ asolano@uned.ac.cr \\ (1) https://orcid.org/0000-0003-0296-4359 \\ Olman Bolaños Ortiz \\ Universidad Estatal a Distancia \\ San José, Costa Rica \\ olbolanos@uned.ac.cr \\ (D) https://orcid.org/0000-0002-8283-2673 \\ Ingrid Monge Rodríguez \\ Universidad Estatal a Distancia \\ San José, Costa Rica \\ imonge@uned.ac.cr \\ (D) https://orcid.org/0000-0001-7294-2900
}

Recibido - Received - Recebido: 04 / 08 / 2020 Corregido - Revised - Revisado: 12 / 04 / 2021 Aceptado - Accepted - Aprovado: 25 / 05 / 2021

DOl: https://doi.org/10.22458/ie.v23i34.3558

URL: https://revistas.uned.ac.cr/index.php/innovaciones/article/view/3558

\begin{abstract}
Resumen: En el sistema educativo costarricense la aprobación de la política educativa resalta el proceso de gestión comunitaria como un elemento para la autonomía del centro educativo. El estudio tiene como objetivo analizar la construcción de indicadores de gestión comunitaria desde la percepción de la persona directora. La metodología se basa en un enfoque mixto con un diseño secuencial; en la fase I se recogió información cualitativa por medio de grupos focales y en la fase II se recogió información cuantitativa por medio de encuesta. Se contó con la participación de personas directoras del Ministerio de Educación Pública, específicamente de las Direcciones Regionales Educativas de Pérez Zeledón y San Carlos. Los resultados muestran la necesidad de construir indicadores de gestión comunitaria que le permitan a la persona gestora de la educación fortalecer la gestión, precisando decisiones y acciones en el ámbito comunitario. Además, para lograr autonomía del centro educativo es importante generar los mecanismos de evaluación y seguimiento.
\end{abstract}

Palabras Clave: Gestión educacional, Participación comunitaria, Indicadores educativos, Política educativa, Educación, Administrador de la educación

Summary: In the Costa Rican educational system, the approval of the educational policyaccentuates the community management processes as an element for the autonomy of the educational institutions. This study aims to analyze community management construction indicators from the head teachers' perspective. The methodology is based on a mixed approach with a sequential design; in phase I, qualitative information was collected through focus groups, and in phase II, quantitative information was survey gathered with the participation of the headteachers of the Ministry of Public Education, specifically of the Regional Educational Councils of Pérez Zeledón and San Carlos. The results show the need to build community management indicators that allow education managers to strengthen management, specifying decisions and actions at a community level. In addition, it is essential to generate evaluation and monitoring mechanisms to achieve autonomy for educational institutions.

Keywords: educational management, community participation, educational indicators, educational policy, education, education administrator 
Resumo: No sistema educacional costarriquenho, a aprovação da política educacional destaca o processo de gestão comunitária como um elemento para a autonomia do centro educacional. O objetivo deste estudo é analisar a construção de indicadores de gestão comunitária a partir da percepção do comitente. A metodologia é baseada em uma abordagem mista com um desenho sequencial; na fase I, as informações qualitativas foram coletadas através de grupos de foco e na fase II, as informações quantitativas foram coletadas através de uma pesquisa. O estudo incluiu a participação de diretores do Ministério da Educação Pública, especificamente das Diretorias Regionais de Educação de Pérez Zeledón e San Carlos. Os resultados mostram a necessidade de construir indicadores de gestão comunitária que permitam ao gerente de educação fortalecer a gestão, especificando decisões e ações no nível da comunidade. Além disso, para conseguir a autonomia do centro educacional, é importante gerar mecanismos de avaliação e acompanhamento.

Palavras chave: gestão educacional, participação comunitária, indicadores educacionais, indicadores educacionais, política educacional, educação, gerente educacional, gestão educacional

\section{INTRODUCCIÓN}

Las personas gestoras de la educación son agentes del sistema educativo, quienes cumplen una tarea central para el cometido y la administración de las distintas instituciones y modalidades educativas. Se enfrentan a diversos retos y desafíos en la práctica de la educación, sobre todo, de cara a los constantes cambios en la sociedad del conocimiento.

Las reorientaciones en las políticas educativas han trazado la ruta de trabajo y desempeño esperado para los directivos escolares. Desde la implementación de la política "El centro educativo de calidad como eje de la educación costarricense" (2008, p. 15) se consolidó un marco de funcionamiento de las instituciones educativas $y$, sobre todo, el rol de los gestores educativos:

La calidad y relevancia de la educación depende de la calidad de quienes cumplen las tareas docentes y administrativo-docentes... Los niveles de calidad que alcance la educación costarricense serán tan altos, como alta sea la calidad de los docentes y directores.

Asimismo, junto a esa directriz, con la "Política curricular, en el marco de la visión educar para una nueva ciudadanía", aprobada por el Consejo Superior de Educación en el 2016, acuerdo 07-64-2016, se complementa el eje de la calidad con cuatro grandes dimensiones: forma de pensar, formas de vivir el mundo (acorde a la integración-ciudadanía global), relaciones con otros y herramientas para integrarse al mundo (el uso de las tecnologías digitales). Por otro lado, con un enfoque que establece perfiles por niveles y contextos educativos, las dimensiones que apuesta la política curricular trazan también habilidades e indicadores para el desempeño de las instituciones educativas.

Los cambios mencionados confluyen en la nueva política educativa "La persona: centro del proceso educativo y sujeto transformador de la sociedad" (2017), entre aspectos destacados establece: un marco filosófico, ejes de desarrollo educativo y, de manera relevante para la gestión, plantea un enfoque de mejora continua y planificación para obtener resultados, construcción de redes, reflejo del entorno, formación continua de los docentes y una cultura de rendición de cuentas.

En consecuencia, las políticas educativas establecen escenarios para el desempeño de la persona gestora de la educación, con un claro énfasis en la importancia de la gestión comunitaria, una tarea orientada a resultados y el vínculo de la experiencia educativa al contexto social.

Informes de carácter nacional como los gestados por el Estado de la Educación desde el 2006, así como internacionales en los que el país ha venido participando: pruebas PISA y el Primer (1997), Segundo (2004-2008) y Tercer (2013) Estudio Regional Comparativo y Explicativo (PERCE, SERCE y TERCE), entre otros, se enfocan en el seguimiento al desempeño del sistema educativo y buscan relacionar los múltiples factores que inciden en el logro de los aprendizajes. Algunas variables que se han considerado son 
las vinculadas con los estudiantes y sus familias; los docentes y las prácticas de clase; y las características de los centros educativos y su vínculo con la comunidad.

En ese sentido, se destaca la investigación desarrollada desde el Programa Estado de la Nación, quienes en el Séptimo Informe Estado de la Educación (2019), trabajan en el seguimiento del desempeño del sistema educativo costarricense. Dentro de sus logros se halla el instaurar una base de datos con información, tanto de primaria como de secundaria, que ha agregado características físicas de los centros educativos y del personal docente. También, la definición de indicadores educativos y muchos otros recursos estadísticos; no obstante, aún no incorporan indicadores de gestión en materia educativa.

En este contexto, el país requiere dar un paso en la construcción de indicadores de gestión de centros educativos en sus distintas dimensiones, esta se constituye en una herramienta que permite mostrar el estado y funcionamiento real del sistema educativo, facilitar su análisis, corregir deficiencias detectadas y diseñar políticas educativas pertinentes a partir de los insumos generados.

Morduchowicz (2006) en su estado del arte sobre la construcción de indicadores en educación, destaca el gran avance en la elaboración de sistemas de indicadores; sin embargo, señala que muchos se enfocan en el gasto educativo y tasas de cobertura. Apunta sobre la necesidad de considerar información que advierta de la pertinencia de la oferta curricular, la participación de los padres de familia en el proceso educativo, el involucramiento y la satisfacción de estudiantes, docentes y familia con el sistema educativo.

Sobre esa línea indicada antes, Ruiz (2014), con la participación de docentes, directivos, estudiantes y otros actores del proceso educativo trabaja en la construcción de indicadores educativos de manera inductiva. Señala que la aportación de estos agentes resulta crucial y, desde otras perspectivas y sentidos, permite construir elementos que trascienden los insumos tradicionales que caracterizan la evaluación de los sistemas educativos, esto abre paso a factores más pertinentes, frescos y novedosos para la toma de decisiones y la puesta en marcha de acciones con miras al mejoramiento de la calidad educativa.

Por su parte, Taccari (2010) señala la diversidad que presenta América Latina en sistemas de indicadores, desde los cuales se despliegan insumos muy robustos para describir y analizar la situación educativa desde distintos contextos y particulares realidades; sin embargo, enfatiza en que sigue mucho camino por recorrer y esfuerzos por realizar para generar indicadores que atiendan los desafíos educativos que enfrenta la educación en América Latina.

Se hace necesario entonces determinar nuevos indicadores que atiendan otras dimensiones de la gestión educativa, los cuales aporten al mejoramiento de lo educativo y superen los insumos tradicionales y preocupaciones típicas de las autoridades educativas, de allí que el objetivo general de este estudio se enmarcara en formular indicadores de gestión comunitaria que permitieran ofrecer las prácticas óptimas para el mejoramiento del desempeño escolar.

Por lo anterior, cabe destacar que el brindar este tipo de insumos al personal directivo les permite ejercer una toma de decisiones más informada y pertinente, así como la posibilidad de dar seguimiento a las variables que establezcan relación con ambientes de aprendizaje en los cuales se propicia el éxito educativo, bajo contextos de inclusión y justicia social; de esta forma, aporta al mejoramiento de la calidad de la educación.

Desde esa perspectiva, la investigación realizada se abocó a buscar una respuesta entre la realidad social y la gestión directiva: ¿cuál es la relación entre el desempeño educativo y los factores asociados a la gestión y vinculación comunitaria de los centros educativos? ¿Cuáles indicadores, a nivel nacional, pueden dar seguimiento al desempeño educativo desde los factores asociados a la vinculación comunitaria de los centros educativos? 
Responder las anteriores interrogantes, permiten comprender la tarea social que tienen las instituciones educativas como instancias mediadoras, sobre las cuales, y de acuerdo con sus potencialidades y posibles puntos de mejora, es posible hablar de una calidad de la educación con carácter de universalidad $y$, por tanto, de incidencia social.

En ese sentido, interesa recuperar el planteamiento anterior mencionado; pues considera los elementos esenciales para tejer puentes hacia un modelo de gestión educativa inclusiva que valore la integración local pensada en un marco de interacción nacional y global. Esto implica la construcción de procesos de identidad y estrategias de vinculación intencionadas en un mundo complejo y diverso.

Una de las principales bases de este estudio se constituye en los lineamientos emanados en la política de Estado "La persona: centro del proceso educativo y sujeto transformador de la sociedad" (2017), entre los que destacan:

- El proceso educativo debe ser coherente en la teoría y la práctica: implica dimensionar la educación como un instrumento de integración social para cerrar brechas creadas por las desigualdades sociales, así como un mecanismo para potenciar el desarrollo nacional sin dejar de lado la formación integral ciudadana, dentro de un marco de respeto por la diversidad cultural y étnica, así como un sentido de responsabilidad de los actuales habitantes con respecto a las necesidades de las futuras generaciones.

- La educación es responsabilidad de todos: se refiere a lo elemental de "una participación activa, creativa, crítica, decisoria y comprometida de los y las estudiantes, de sus familias, de quienes en el centro educativo ejercen las funciones docentes, técnico-docentes y administrativo-docentes y de la comunidad donde está inserto" (p. 13), sin dejar de lado la responsabilidad institucional para resolver las necesidades y brindar apoyo y acompañamiento a las instituciones educativas.

- La educación debe estar centrada en el estudiante como sujeto activo y responsable de los procesos de enseñanza y aprendizaje: pensar el sujeto educativo y el reconocimiento de sus derechos y procesos individuales y colectivos es la base sobre la cual se articula la dinámica escolar.

- La calidad y relevancia de la educación dependen de la calidad de quienes cumplen las tareas docentes y administrativo-docentes: pensado desde la formación inicial universitaria hasta el desarrollo profesional, el componente humano resulta esencial para llevar a cabo cualquier proyecto educativo, y, a su vez, involucra la gestión en los centros educativos requerida para poder lograr una educación de calidad.

- La educación de calidad debe sustentarse sólidamente en el empoderamiento de la comunidad educativa: el centro educativo, como eje de la calidad, involucra necesariamente el empoderamiento de la comunidad educativa como eje contextualizado de los procesos educativos, para lo cual es preciso que "la comunidad se apropie -haga suyo- el centro educativo y participe activa, crítica y creativamente en las decisiones institucionales que conducen a la búsqueda permanente de una mejor calidad y equidad educativas" (p. 16), esto implica replantear una cultura institucional burocrática y centralista.

- La gestión educativa debe estar en función del proceso educativo: estos lineamientos requieren necesariamente nuevas formas de gestión, las cuales involucren procesos de reflexión institucional para trazar rutas que permitan mejorar los logros educativos. Se fundamenta en dos dimensiones:

- La educación debe ser apoyada por una gestión ágil, eficiente y amable (p. 17).

- La educación debe estar sustentada en el uso activo de la investigación educativa, la evaluación y la rendición de cuentas (p. 19). 
Dicha política delinea con claridad que la gestión educativa deberá considerar como tarea elemental el involucramiento y la participación activa de la comunidad, tanto a lo interno como a lo externo de los muros de la institución educativa. De esta manera, dichos lineamientos se constituyen en insumos directos para la formulación y el tratamiento de indicadores, que permitan a las personas gestoras de la educación guiar y monitorear los efectos de sus acciones hacia el alcance de lo esperado con esta política.

En cuanto a los referentes teóricos considerados para este proceso investigativo, como lo indican Ramírez y Quesada (2019) lograr una mejor comprensión del sistema educativo costarricense, requiere la construcción de indicadores que permitan una representación más completa de la realidad socioeducativa. Avanzar hacia la delimitación de indicadores es contar con información para la toma de decisiones.

Según Quesada y Ramírez (2019) citando Antúnez (1998), la palabra "gestión" implica describir o analizar el funcionamiento de la entidad escolar. En consecuencia, es sinónimo de integración con la realidad material, cultural, organizativa y pedagógica.

La gestión constituye el articular entre el ámbito educativo y los diferentes sectores sociales. Asimismo, involucra un conjunto de actuaciones que se desarrollan en el centro como expresión del gobierno institucional, bajo la conducción y la responsabilidad de la persona directora, para definir sus objetivos y diseñar la naturaleza y el desarrollo de las tareas para alcanzarlos. Implica la participación de todos los miembros en la planificación, ejecución y control de las decisiones y acciones que se toman en los ámbitos: curricular, servicios, recursos y comunidad, en grado y forma acorde con sus capacidades, competencias y roles (Bellido, Díaz, Morales \& Pino, 2009).

La gestión educativa resulta esencial en el desarrollo del proyecto social y la respuesta a las necesidades, aspiraciones y propuestas de la población en los diversos espacios. Cuenta con diferentes dimensiones: administrativa, manejo de talento humano, curricular y comunitaria. Todas son dinámicas, coexisten, interactúan y determinan la organización y el funcionamiento cotidiano de la institución educativa.

Para el abordaje de las distintas dimensiones de la gestión se utilizan indicadores, los cuales representan mecanismos para referirse a la parte técnica y política y, en general, a características del sistema educativo. Los indicadores constituyen medios para interpretar la realidad socioeducativa y facilitan la caracterización de situaciones académicas, laborales, de aprendizaje, del contexto, entre otras (Morduchwicz 2006).

Ahora bien, se toma como referente el modelo de gestión estratégica situacional, este comprende la parte técnica, la planeación, el área organizativa e institucional, y, se parte de la importancia del análisis y el abordaje de las problemáticas en los espacios socioeducativos (Casassus, 1997, p. 22).

Según lo anterior, la perspectiva estratégica situacional brinda una mirada crítica de los problemas socioeducativos; en otras palabras, es un cuestionamiento a la coyuntura y el enfoque de la gestión como un proceso, desde la realidad actual hacia los objetivos y metas esperadas, lo cual incluye el ámbito de gestión comunitaria que las personas directoras de la educación deben implementar.

\section{Gestión comunitaria}

Es importante considerar la diferenciación entre lo que entendemos como la "comunidad educativa" y "comunidad" en tanto territorio. Para la primera, dentro del campo educativo nos estamos refiriendo a ese conjunto de relaciones existentes entre la dirección del centro educativo, el profesorado, el estudiantado y sus respectivos núcleos familiares tradicionalmente representados por la figura del padre (más común, de la madre); asimismo, intervienen otros actores, como el personal de apoyo pedagógico o de mantenimiento del centro escolar. Desde esta primera aproximación, se ha establecido el desarrollo de proyectos educativos, para incidir en las instituciones primarias de socialización, la familia y el centro educativo. 
Una segunda aproximación es cuando se refiere a la comunidad; es decir, cuando se piensa en los extramuros, en tanto territorio y, desde la perspectiva de las ciencias sociales, este planteamiento se complejiza. Tampoco existe un consenso de cómo pensar el territorio o la comunidad como tal.

Por lo general, en la práctica predomina el análisis de la dimensión económica y la social. La comunidad en tanto territorio está geográficamente delimitada; la identificación de los actores se realiza desde lo que la institución reconoce como legítimos, los hay públicos y privados, está la sociedad civil y las instituciones estatales. Esta concepción de territorio prima el modo de operar de las instituciones, de las agencias internacionales $y$, en general permite, hasta cierto punto, efectuar una práctica de gobernanza.

La principal problemática de este enfoque es que deja por fuera la conflictividad, los procesos de construcción de identidad y las múltiples escalas en las que operan los actores en el territorio: desde aquellos que realizan incidencia en el plano local, como pueden ser una iglesia, una persona líder comunal, hasta los que tienen un campo de acción en la escala nacional y global. Estas múltiples escalas representan diferentes escenarios para establecer alianzas; es decir, dejamos por fuera las relaciones de poder a lo interno del territorio (Krause,2001; Torres, 2002; Jiménez, 2011) y cómo estas relaciones de poder inciden en el desarrollo o no de un determinado proyecto de vinculación-acción.

Por último y central, la gestión comunitaria corresponde a la manera en que la entidad educativa se vincula con la comunidad, toda vez que comprende las necesidades, condiciones y demandas de esta, para integrar y dar respuestas desde el espacio educativo; en término generales, es el vínculo de institución con el entorno, en la búsqueda siempre de establecer alianzas, redes para mejorar las condiciones socioeducativas. (UNESCO, 2011).

\section{Comunidades de aprendizaje como modelo de vínculo escuela-comunidad}

Desde esta perspectiva y un trabajo con un enfoque que potencie la inclusión, la interculturalidad y la participación comunitaria, es que se desarrolla una orientación de labor que busque dar cuenta de las realidades sociales, políticas y económicas en las cuales transcurren los procesos de enseñanza y aprendizaje.

En este marco descrito en el párrafo anterior, las comunidades de aprendizaje tienen su fundamento en las profundas transformaciones del entorno y cómo construir procesos que partan del marco de posibilidades dadas. Los conceptos e ideas claves sobre los cuales deben basarse, son los siguientes (González, 2004, Elboj, 2003, Mingorance, 2009, Palomar, 2010):

- La comunidad de aprendizaje es un proyecto de transformación social y cultural: debe repensar las prácticas educativas y darles significado en un proceso inclusivo y de justicia social.

- Las comunidades de aprendizaje son también un proyecto de centro educativo: por su interés de contribuir con el alcance de objetivos de formación y aprendizaje mediante la sinergia activa de los miembros de la comunidad.

- Las comunidades de aprendizaje son un proyecto del entorno: tiene su sustento en el desarrollo local y comunitario en el cual se integran las diversas instituciones que tienen injerencia en la comunidad. El proyecto que surge tiene como objetivo construir un proyecto educativo y cultural que parta de las necesidades y las posibilidades de su propio entorno.

- Las comunidades de aprendizaje tienen como objetivo conseguir una sociedad de la información para todas las personas: niños, jóvenes y adultos enriquecen sus saberes en diálogos intergeneracionales y entre pares. 
- Las comunidades de aprendizaje se desarrollan mediante una educación participativa de la comunidad que se concreta en todos los espacios, incluida el aula: se da un aprovechamiento de todos los recursos disponibles y de capital humano con el que cuentan las comunidades y su entorno. Es, por tanto, participativo y democrático.

Krichesky (2006, p. 30) realiza una síntesis de lo que se entiende por comunidad de aprendizaje:

Una comunidad de aprendizaje se sustenta en un proceso de desarrollo local y comunitario en el que se articulan diversas instituciones (académicas, sociales, comunitarias) que tienen injerencia en la comunidad para construir un proyecto educativo y cultural que parta de las necesidades y posibilidades de la comunidad. Dicha articulación permite un mayor aprovechamiento y desarrollo de todos los recursos (humanos, materiales, culturales y sociales) disponibles en cada comunidad y que pueden hacer posible una educación para todos. En una comunidad de aprendizaje participan niños, jóvenes y adultos profundizando el aprendizaje intergeneracional y entre pares, y el potencial de los jóvenes como educadores y agentes activos de su propia educación y del desarrollo de la comunidad.

En esta línea de trabajo es que se comprenden los procesos y las articulaciones entre los centros escolares y su entorno comunitario, en la medida en que se constituyen para construir prácticas que fortalezcan la inclusión e interculturalidad, a partir de la participación comunitaria. En concordancia con lo anterior se destacan los indicadores de gestión comunitaria propuestos por Quesada y Ramírez (2019).

TABLA 1

Dimensión de gestión comunitaria

\begin{tabular}{llll}
\multicolumn{1}{c}{ Indicador } & \multicolumn{1}{c}{ Aspecto de medición } & Fuente \\
$\begin{array}{lll}\text { Acciones educativas } \\
\text { comunitarias }\end{array}$ & $\begin{array}{l}\text { El objetivo es generar espacios de comunicación e intercambio tendientes a } \\
\text { mejorar las condiciones educativas de los niños/jóvenes, y construir una retroali- } \\
\text { mentación cultural mutua. }\end{array}$ & González (2004) \\
$\begin{array}{lll}\text { Acciones referidas a } \\
\text { la inclusión escolar }\end{array}$ & $\begin{array}{l}\text { Proyectos educativos entre la institución y las organizaciones comunales como } \\
\text { mecanismo inclusivo, posibilita la pronta visualización de los niños en situación } \\
\text { de vulnerabilidad educativa y aquellos que se encuentran por fuera de la escuela. }\end{array}$ & González (2004)
\end{tabular}

Fuente: tomada de Quesada y Ramírez (2019) citando a González (2004).

\section{MATERIALES Y MÉTODOS}

El objetivo de la investigación fue el construir indicadores de vinculación con la comunidad en los centros educativos. Para llevar a cabo este estudio se realizó la investigación con un enfoque mixto y un diseño de ejecución secuencial, según Creswell, (2013) citado por Hernández, Fernández y Baptista (2014):

En una primera etapa se recolectan y analizan datos cuantitativos o cualitativos, y en una segunda fase se recaban y analizan datos del otro método. Normalmente, cuando se recolectan primero los datos cualitativos, la intención es explorar el planteamiento con un grupo de participantes en su contexto, para posteriormente expandir el entendimiento del problema en una muestra mayor y poder efectuar generalizaciones a la población (p. 534). 


\section{Fase I. Enfoque cualitativo, método estudio de caso}

La fase I asumió el método estudio de caso, el cual lo define Bernal (2010) como una modalidad investigativa que pretende detallar a la unidad de análisis dentro de un contexto específico, con características propias. Según el autor, el estudio de caso posee un procedimiento metodológico que estudia en profundidad el tema con la unidad de análisis, se recolectan datos, se analizan, interpretan, validan y se redacta el caso (p. 116).

\section{Fase II. Enfoque cuantitativo, método encuesta}

La fase Il asumió el método basado en encuesta, el cual lo definen Casas, Repullo y Donado (2003) como una de las técnicas más utilizadas para obtener datos de una forma rápida y eficaz. Permite al investigador indagar sobre opiniones por medio de preguntas cerradas que se desprenden de los objetivos de la investigación.

\section{Participantes}

Los participantes fueron personas directoras de instituciones educativas del Ministerio Educación Pública (MEP), tanto de primaria como secundaria, pertenecientes a las Dirección Regional de Educación (DRE) Pérez Zeledón, así como DRE San Carlos. Se seleccionaron estas zonas, por contar con características similares y, al mismo tiempo, diversas a las compuestas a nivel nacional; es decir, unidocentes, indígenas, secundaria académica, secundaria técnica, secundaria agropecuaria, modalidades para jóvenes y adultos, entre otros.

Para la fase cuantitiva, la muestra se seleccionó a través de un muestreo no probabilístico, intencional y por conveniencia, estuvo constituida por 81 administradores educativos de la Dirección Regional de Pérez Zeledón.

\section{Técnicas de recolección}

Dentro del proceso de investigación se utilizaron dos técnicas para recolectar la información: grupos focales y encuesta.

Grupos focales: definida por Abarca, Alpízar, Sibaja y Rojas (2013) como una "entrevista grupal". El término focal "obedece a que la técnica se limita al estudio de un número reducido de temas, incluso quien modera debe mantener a los participantes circunscritos en los límites del conjunto de temas" (p. 161).

Encuesta: según López-Roldán y Facheli (2015), es una técnica de recogida de datos de manera sistemática sobre diversos conceptos derivados de una investigación teórica previa, conformada por un cuestionario que permite acumular información por medio de su respectiva distribución (p. 8). Se elaboró un instrumento en línea mediante la herramienta SurveyMonkey', el instrumento se constituyó de once ítems cerrados, en los cuales los informantes debían seleccionar aquella categoría que mejor representara su respuesta. Lo anterior mediante una escala de Likert.

\section{Proceso de ejecución}

El proceso de investigación se desarrolló en cuatro etapas: la primera enfocada en la revisión teórica sobre los indicadores y el ámbito comunitario. La segunda, centrada en la propuesta metodológica, y la tercera dedicada al trabajo de campo. Este último, lo constituyó el desarrollo de un grupo focal en la Dirección Regional de Educación San Carlos y se aplicó una encuesta dirigida a personas administradoras de la educación de la zona de Pérez Zeledón. El proceso finaliza con el análisis de datos cualitativos obtenidos a partir del grupo focal y procesados por medio de la herramienta Atlas.ti, así como la información cuantitativa obtenida a partir de la encuesta, cuya herramienta de aplicación (SurveyMonkey) permitió generar informes estadísticos por ítem, lo cual facilitó la identificación de los hallazgos más relevantes mediante representaciones gráficas. 


\section{DISCUSIÓN DE RESULTADOS}

Se comprende la dimensión comunitaria como aquella basada en la relación que establece el centro educativo con respecto a la comunidad en la cual se encuentra. El enfoque adoptado para esta investigación es de carácter horizontal, en el que la comunidad y el centro educativo intercambian criterios y participan activamente en el análisis de las problemáticas educativas, las propuestas y la ejecución de acciones que busquen solventar dichas situaciones, para ello se toman en cuenta sus características particulares comunitarias.

\section{Resultados Región Educativa de San Carlos}

Del trabajo en los grupos focales en la zona de San Carlos se definieron dos indicadores: las acciones comunitarias educativas, aquellas que tienen como objetivo generar espacios de comunicación e intercambio tendiente a mejorar las condiciones educativas de los niños/jóvenes, y construir una retroalimentación cultural mutua, y las acciones referidas a la inclusión escolar, en la cual se destacan los proyectos educativos entre la institución y las organizaciones de la comunidad como mecanismo de inclusión, además posibilita la pronta visualización de los niños en situación de vulnerabilidad educativa y a quienes se encuentran fuera de la escuela.

Producto del criterio de las personas informantes y en función de los indicadores ya mencionados, se lograron extraer distintas categorías que permitieron organizar y comprender los elementos que toman especial relevancia en el marco de la gestión comunitaria, en este contexto de estudio específico. A continuación, se presentan los resultados obtenidos.

\section{Acciones para la construcción de espacios centro educativo-comunidad}

En esta categoría se determina como meta identificar los aspectos que se toman en cuenta para la construcción de espacios donde se invite al trabajo conjunto entre la población de la comunidad y el cuerpo docente/administrativo del centro educativo. En la figura 1 se pueden apreciar los criterios expresados por las personas directoras:

Los directivos escolares en la Regional de San Carlos resaltan la necesidad de generar procesos de diagnóstico comunitarios para elegir las prioridades, los contenidos, las finalidades y las posibles rutas de acción e interacción que se puedan establecer con las familias y los agentes de la comunidad. Se rescatan las propuestas referidas a metodologías de participación; tal es el caso de los directores que manifestaron como necesario efectuar visitas al hogar, lo que a su vez requiere un compromiso docente.

Esto coincide con lo que afirma Aravena-Castillo (2020) sobre la gestión comunitaria

De forma que una habilidad clave que requieren desarrollar los líderes escolares es poder leer el contexto en el que se desempeñan e identificar las necesidades de desarrollo de sus actores. Es decir, poseer herramientas para analizar y observar de manera integrada una realidad compleja y altamente dinámica. Aprender a leer los factores contextuales que inhiben o favorecen la mejora escolar es una tarea crítica para los líderes escolares (p. 7). 
Figura 1. Opinión de los informantes sobre la dimensión comunitaria DRE San Carlos

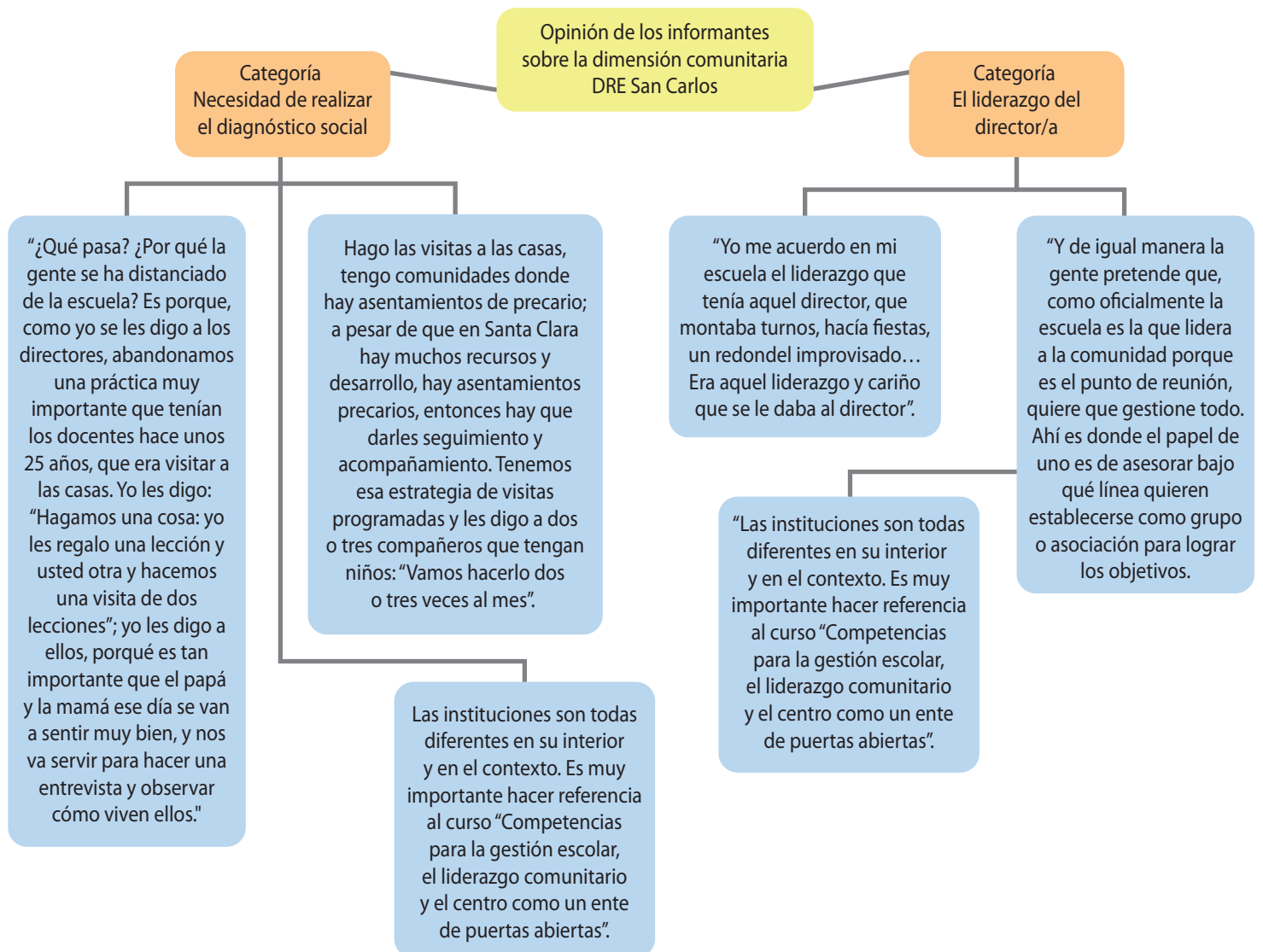

Fuente: información suministrada por los participantes del estudio "Construcción de indicadores para la gestión administrativa y curricular de centros educativos para el mejoramiento del desempeño educativo", en octubre de 2018.

En relación con el factor del liderazgo de la persona directora de la institución y como esta puede transformar la dinámica del centro educativo y la comunidad, emerge una serie de factores; para ello se requiere establecer principios como los mencionaron, entre los cuales se cita: "proyección, divulgación, comunicación, consideración, identificación, liderazgo, transparencia".

La labor de la persona directora abarca más allá de la gestión administrativa en un proyecto de vínculo con la comunidad. Significa construir un liderazgo para forjar consensos, puentes de comunicación y saber efectuar una lectura de los intereses y los resultados esperados de los diferentes actores. El éxito de un proyecto educativo está en función de qué tanto se apropien los diferentes actores al mismo, qué tanto sus marcos valorativos se acerquen o se alejen de los objetivos planteados por la institución.

\section{Las Juntas y el Patronato Escolar}

Las Juntas de Educación constituyen instancias de participación y apoyo a las instituciones educativas, en lo esencial en coordinación con los directores, constituye un grupo, en la primera línea de atención de necesidades particulares; por otro lado, los Patronatos Escolares son instancias auxiliares de las Juntas de Educación, orientadas a promover la mejora del contexto socioeducativo (Código de Educación).

En relación con los directores de la zona de San Carlos, respecto a las Juntas de Educación y el Patronato Escolar, mencionan los siguientes criterios de acuerdo a la figura 2. 
Figura 2. Opinión de los informantes sobre la dimensión comunitaria DRE San Carlos

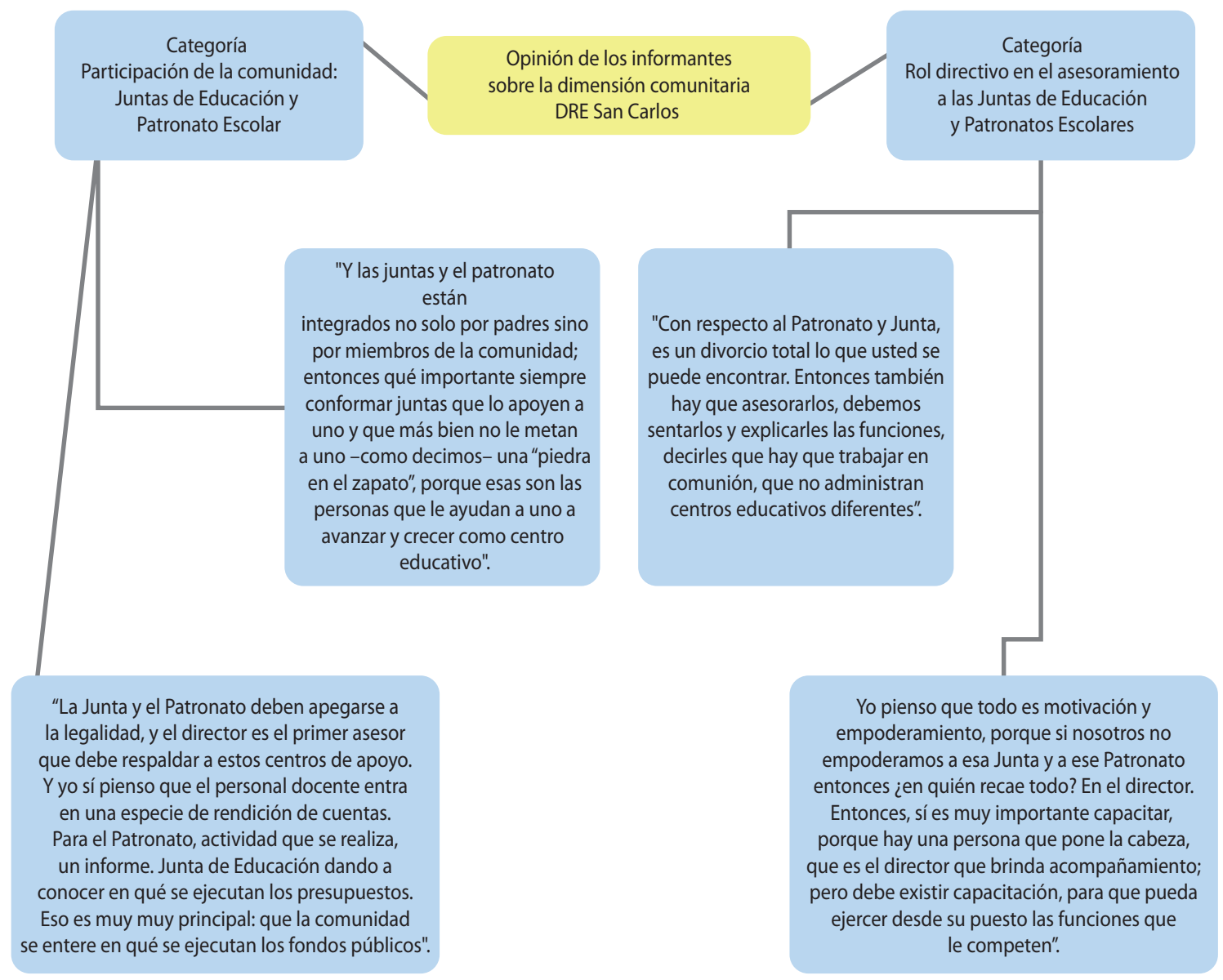

Fuente: información suministrada por los participantes del estudio "Construcción de indicadores para la gestión administrativa y curricular de centros educativos para el mejoramiento del desempeño educativo", en octubre de 2018.

En los resultados anteriores se manifiesta la presencia de una tensión en diferentes lugares del quehacer directivo y su relación con la comunidad, entre el enfoque de trabajo burocrático-administrativo y horizontal-colaborativo. En el primero, prima la noción normativa de las instituciones formales; por tanto, los actores participan en las actividades de la escuela y contribuyen en el sentido más concreto y pragmático de la palabra, y dentro del marco de legalidad. En la segunda, se abren las posibilidades de propiciar vínculos más allá de los establecidos, se innova en la gestión del quehacer directivo.

Una vez más aparece el rol directivo y su necesidad de construir liderazgos que acompañen a los Patronatos Escolares y las Juntas de Educación. Por un lado, ante la necesidad de trabajar aspectos relacionados con la construcción de relaciones humanas necesarias para proyectar las iniciativas educativas. Por otro, también emerge la necesidad de fortalecer procesos de capacitación y desarrollo de competencias para instancias de apoyo esenciales para el éxito de la gestión de los directivos.

En el contexto de trabajo con las Juntas de Educación y los Patronatos Escolares, resulta esencial el liderazgo distribuido que implica la generación de una cultura organizacional, de compromiso e implicación alrededor del proyecto institucional, en esa ruta resultan claves las habilidades de las personas directivas escolares. (Murillo, 2006). 


\section{El ámbito normativo para la participación comunitaria}

El ámbito normativo como factor que puede potenciar o limitar la participación de la comunidad en algunos procesos de la institución educativa, desde la perspectiva de los directivos, presenta diferentes aspectos, tal como se observa en la figura 3.

Figura 3. Opinión de los informantes sobre el ámbito normativo de la dimensión comunitaria DRE San Carlos

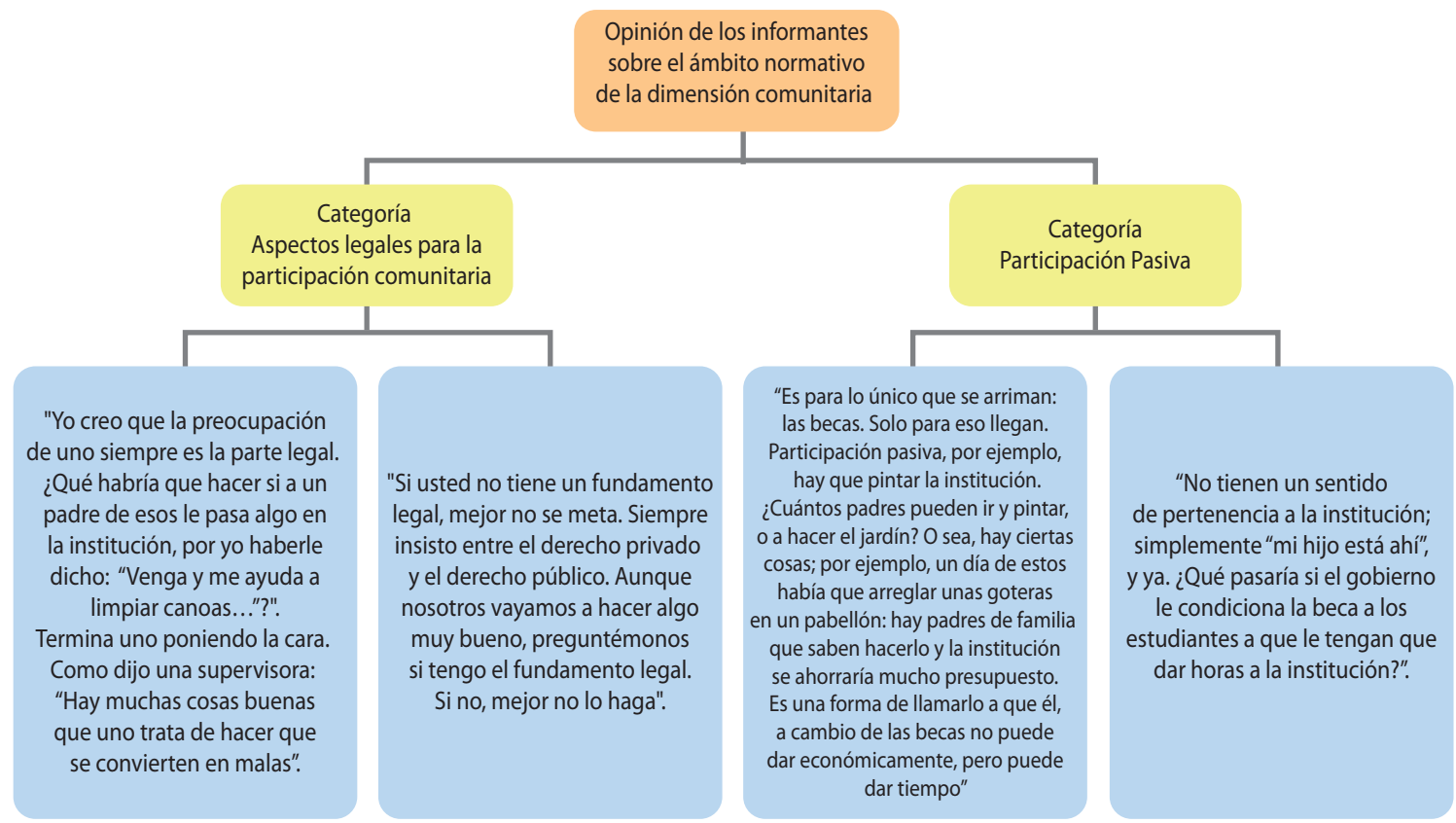

Fuente: información suministrada por los participantes del estudio "Construcción de indicadores para la gestión a dministrativa y curricular de centros educativos para el mejoramiento del desempeño educativo", en octubre de 2018.

De la información esgrimida en la figura anterior, sobre el tema normativo emerge que la creación de vínculos entre el centro educativo y su comunidad se realiza desde un espacio institucionalizante, el cual favorece la reproducción de formas verticales y burocráticas de participación comunitaria. Tal caracterización plantea desafíos en el momento cuando se busquen potenciar otras formas de participación comunitaria y la construcción de indicadores para favorecer experiencias democráticas a nivel institucional.

Por tanto, resulta central propiciar la vinculación comunitaria para favorecer la toma de decisiones y el desarrollo de actividades, la cual considere demandas, las exigencias entre la escuela y la comunidad, siempre con el norte en favorecer la participación. (Ramírez, García y Cruel, 2017).

\section{Espacios de comunicación con la familia}

La rendición de cuentas hacia las familias es citada por las personas directoras como una de las estrategias de seguimiento más importante a considerar en el fortalecimiento de las relaciones entre el centro educativo y la comunidad. En la figura 4 se sintetizan los principales criterios. 
Figura 4. Opinión de los informantes sobre los espacios de comunicación con la familia DRE San Carlos

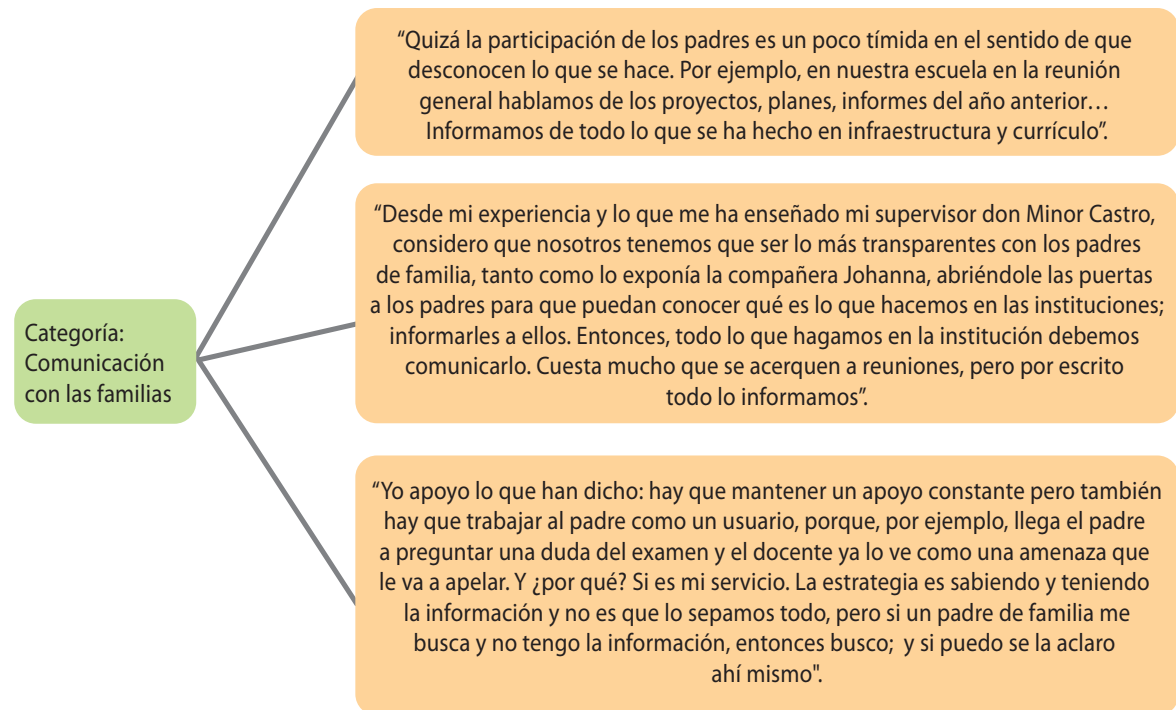

Fuente: información suministrada por los participantes del estudio "Construcción de indicadores para la gestión administrativa y curricular de centros educativos para el mejoramiento del desempeño educativo", en octubre de 2018.

De la información obtenida en el grupo focal en la zona de San Carlos, referente al tema de la comunicación con las familias, es indudable que las acciones deben impulsarse desde el propio centro educativo, sean espacios de interacción, mecanismos de rendición de cuentas y seguimiento. Nuevamente, son fundamentales el liderazgo y la generación de estrategias que permitan el diálogo, tanto del directivo escolar como de los docentes y otras instancias educativas.

Tal como lo plantean Rivera, Rojas, Ramírez y Álvarez (2005) la comunicación representa una herramienta de gestión que permite generar apertura, oportunidades de participación para cimentar valores de la organización y sentido de pertenencia entre los diversos actores, lo cual constituye un reto para las personas directoras y supervisoras de la educación.

\section{Involucrar a las familias en la vida escolar}

Las personas directoras externaron sus criterios con respecto al involucramiento de las familias en la vida escolar, en lo que concierne no solo al desarrollo del currículo, también al seguimiento y los proyectos propuestos por la institución educativa. La figura 5 resume los principales elementos destacados por los informantes.

De la figura anterior emerge una serie de elementos sobre la participación de las familias en la vida educativa. Por un lado, los grupos familiares interactúan con el centro educativo en actividades formales e institucionalizadas, efemérides, ferias o celebraciones culturales. Por otro, el involucramiento en procesos curriculares, de toma de decisiones y resolución de problemas de las instituciones educativas tiende a ser limitado; en tal sentido, no se presenta un vínculo efectivo y articulado en torno a un proyecto educativo o de desarrollo.

Las personas directoras de la educación y los supervisores, junto con otros actores educativos desde una cultura de diálogo, reconocimiento y respeto a la diversidad, intercambio de experiencias contribuyen a potenciar la participación y un trabajo colaborativo que favorece la mejora escolar (Pincheira, 2010). 
Figura 5. Opinión de los informantes sobre la participación de las familias en la vida escolar Región Educativa San Carlos

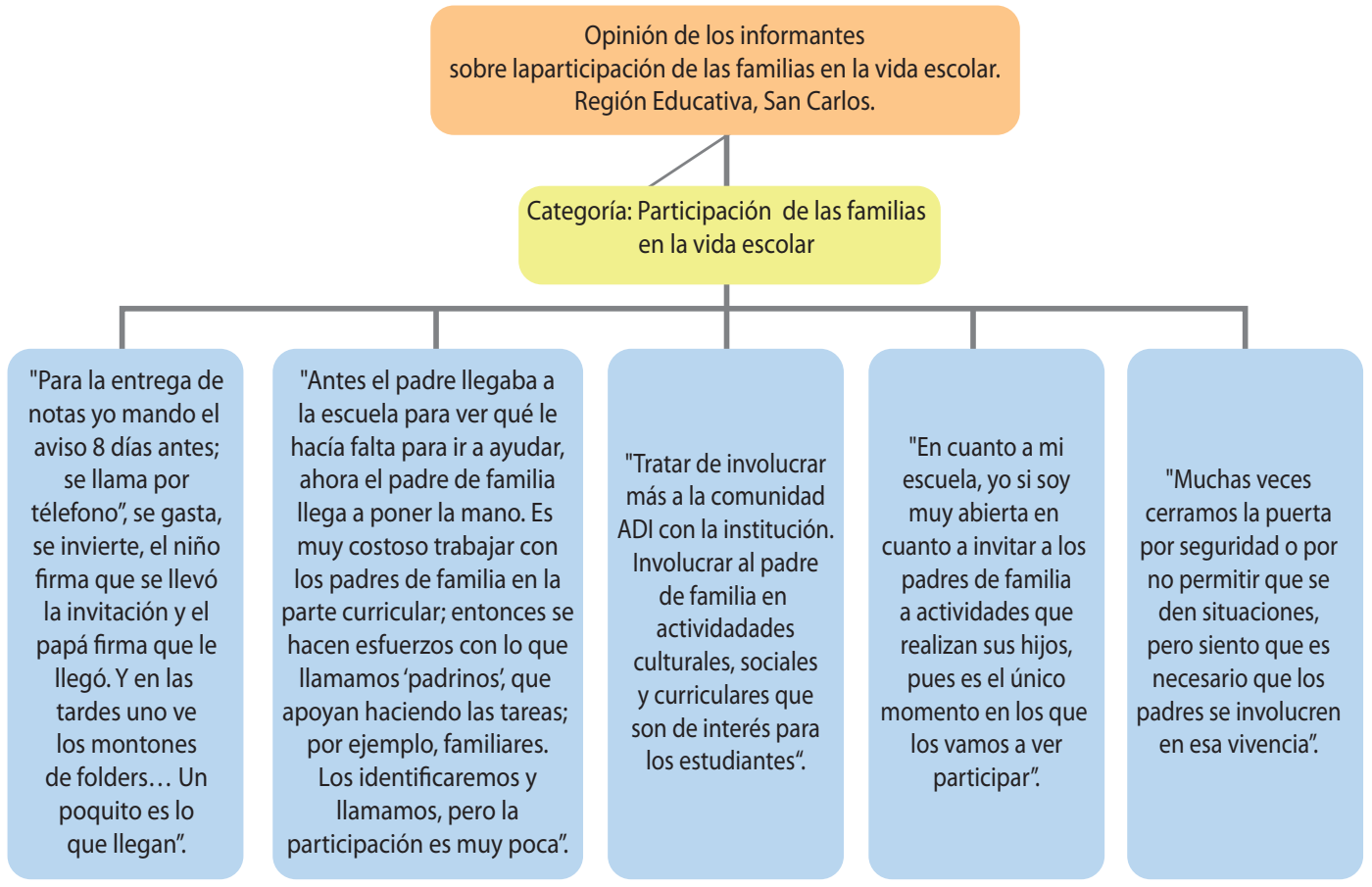

Fuente: información suministrada por los participantes del estudio "Construcción de indicadores para la gestión administrativa y curricular de centros educativos para el mejoramiento del desempeño educativo", en octubre de 2018.

\section{Involucrar a los agentes sociales en el entorno escolar}

Las personas directoras externaron sus criterios con respecto al involucramiento de otros agentes sociales en la vida escolar, en lo que concierne no solo al desarrollo del currículo, también en el seguimiento y los proyectos propuestos por la institución educativa, tal como se detalla en la tabla 2.

De los criterios considerados para el presente estudio, se destacan algunos elementos comunes y, en ese sentido, es el liderazgo directivo, sin este no sería posible pensar procesos que involucren a la comunidad y las familias.

Otro de los elementos relevantes es la continua tensión que surge entre los mecanismos formales que canalizan la acción directiva y la necesidad de innovar otras formas de relación e involucramiento en la dinámica del centro educativo.

Por tanto, desde las instituciones educativas y, de manera particular, desde la gestión es fundamental el liderazgo dinámico y efectivo, que oriente hacia prácticas educativas eficientes y agrupe a los miembros de la comunidad educativa hacia objetivos comunes. (Contreras, 2019). 
TABLA 2

Opinión de los informantes sobre la vinculación de agentes sociales al entorno escolar DRE San Carlos
Categoría
Criterios de los informantes

"Ya he estado en varias escuelas como directora y yo lo que llego es a presentarme a mi comunidad, a buscar cuáles organismos existen en la comunidad para ofrecerles a ellos mis servicios y solicitarles que de una u otra forma se acerquen a colaborar".

"Hay que andar buscando colaboradores de la comunidad porque no es suficiente. Hay que echarse al agua y poder involucrar a la comunidad".

"En mi comunidad como fuerza viva, legal, formal, está la ASADA. Me he encontrado con la particularidad

Participación de los agentes sociales en la vida escolar que a nivel comunal no hay organización, por lo que la ASADA va a ser un detonante para realizar proyectos en conjunto. EI TEC, que siempre nos apoya en proyectos de infraestructura y reparación de mobiliarios. La ASADA, que viene a dar charlas a los niños (están ya programadas por grados y niveles durante todo el año). Hay una ventaja de tener a la par el EBAIS, que tiene una estrategia directa con la comunidad".

"Santa Clara tiene a su alrededor una universidad con la cual la escuela ha hecho alianzas. En la parte pedagógica trabajamos con niños a los que preparamos todo el año, digamos los de sexto, que puedan hacer admisión directa para el colegio agropecuario. En el mes de agosto tenemos un convivio con padres de familia que es un éxito: se comprometen los padres, la Junta y el Patronato. Que el Patronato y la Junta es muy difícil porque, de verdad, es por convencimiento que se trabaja con ellos... Que sientan que uno está ahí y retomemos los Juegos Cooperativos".

Fuente: información suministrada por los participantes del estudio "Construcción de indicadores para la gestión administrativa y curricular de centros educativos para el mejoramiento del desempeño educativo", en octubre de 2018.

\section{Acciones referidas a la inclusión escolar}

La inclusión educativa representa un proceso para responder y atender a los requerimientos de la comunidad educativa (estudiantes esencialmente en sus distintos niveles), implica prácticas desde la gestión y las acciones docentes para comprender, de manera pertinente, el contexto y su diversidad (Sánchez, 2018).

Respecto al tema de acciones para la inclusión educativa, los directivos en la zona de San Carlos apuntan distintos aspectos, que se desglosan en la tabla 3.

TABLA 3

Opinión de los informantes sobre acciones de inclusión escolar DRE San Carlos

\section{Categoría Criterios de los informantes}

"En mi escuela hay 2: uno de manejo de residuos porque la comunidad tiene un centro de acopio -para nosotros es muy fácil acuerpar ese trabajo, el manejo de los residuos para el reciclaje-. Y segundo, los programas de cómputo para personas de la comunidad en coordinación con COOPELESCA. Alfabetización tecnológica, porque había gente que no sabía ni encender la computadora.

Tenemos el laboratorio Movillab y le damos un uso en capacitación tecnológica para la comunidad. Es muy cansado porque hay que estar ahí; el gasto de recursos se dispara: por ejemplo, la electricidad en esa época, el uso de implementos de limpieza se dispara".

Proyectos "Y otro proyecto que ha acercado la escuela a las personas de la comunidad ha sido el huerto escolar. socioeducativos Cuando empezó a hacerse había muchas compañeras que decían "No, eso no te va a servir", pero inclusive se han organizado para venir sábados y organizarse".

"Vamos a empezar con la parte bonita, la huerta escolar. El circuito que yo dirijo se ha caracterizado por tener huertas escolares diferenciadas, y nos ha tocado sufrir, pero hemos ido investigando y poniendo en práctica lo que queremos ajustar de una huerta escolar. Y nos ha servido mucho para atraer a las madres de familia, porque generalmente hay un recargo para que atienda la huerta".

"Otra estrategia también es preparar a la escuela para las fiestas patrias. Ayer fue un día importantísimo porque tenía así de padres limpiando la institución. Adecuamos la jornada, los padres empiezan a trabajar, y en la tarde todos nos integramos en grupo".

Fuente: información suministrada por los participantes del estudio "Construcción de indicadores para la gestión administrativa y curricular de centros educativos para el mejoramiento del desempeño educativo", en octubre de 2018. 
De los elementos abordados sobre la inclusión escolar, el más común es que los actores externos participan en actividades vinculadas a medio ambiente y acciones dentro del calendario escolar. Los actores externos representan instancias de apoyo ante necesidades socioeducativas, y la presencia de estos depende de la coordinación e impulso de la persona directora.

\section{Resultados en la Región Educativa de Pérez Zeledón}

El primer indicador a destacar es la importancia manifestada por las personas directoras en vincularse con los diversos actores comunitarios enlistados en el cuestionario. A partir de las opiniones de los encuestados, esta vinculación puede agruparse según tres tipos de actores. En el primer caso, los actores de carácter formal, compuestos por instituciones del Estado, municipalidades y asociaciones de desarrollo, los cuales conforman un ecosistema institucional que cumple funciones y mandatos legales concernientes a áreas de interés para los centros educativos. En el segundo caso, las organizaciones de la sociedad civil y el sector productivo (cooperativas y sector empresarial), en el cual más del $30 \%$ de los participantes consideraron importante tener un fuerte vínculo. Finalmente, se desprende de los resultados que organismos internacionales no se consideran actores locales por los participantes.

Figura 6. Opinión sobre grado de importancia de la participación comunitaria DRE Pérez Zeledón

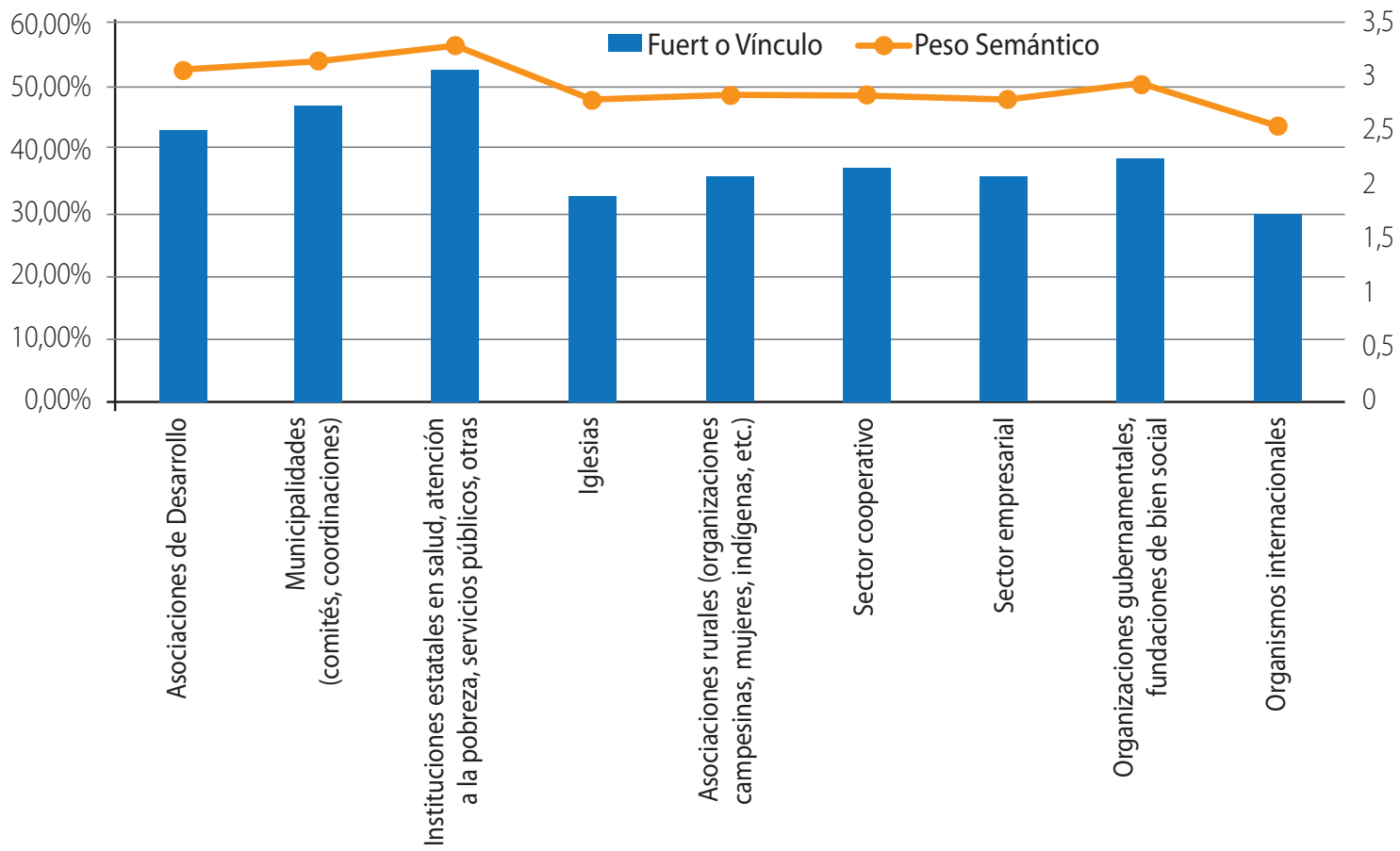

Fuente: información suministrada por los participantes del estudio "Construcción de indicadores para la gestión administrativa y curricular de centros educativos para el mejoramiento del desempeño educativo", en marzo de 2019.

Para el presente estudio resultó interesante indagar sobre qué tanto participan los diferentes actores locales en los procesos internos de los centros educativos consultados. Para este caso, los indicadores mostraron un comportamiento diferente: los valores con menos peso son los que adquirieron relevancia, esto dio como hallazgo que la vinculación de los diferentes actores locales en las decisiones del centro es una deuda pendiente en nuestros sistemas escolares. 
El indicador que mayor participación relativa presenta es el desarrollo y mantenimiento de la infraestructura educativa y la gestión de proyectos de inclusión y promoción educativa. En contraste, el de menos peso es en la gestión del currículo.

Figura 7. Opinión sobre grado de participación de los actores comunitarios en la gestión del centro educativo. DRE Pérez Zeledón

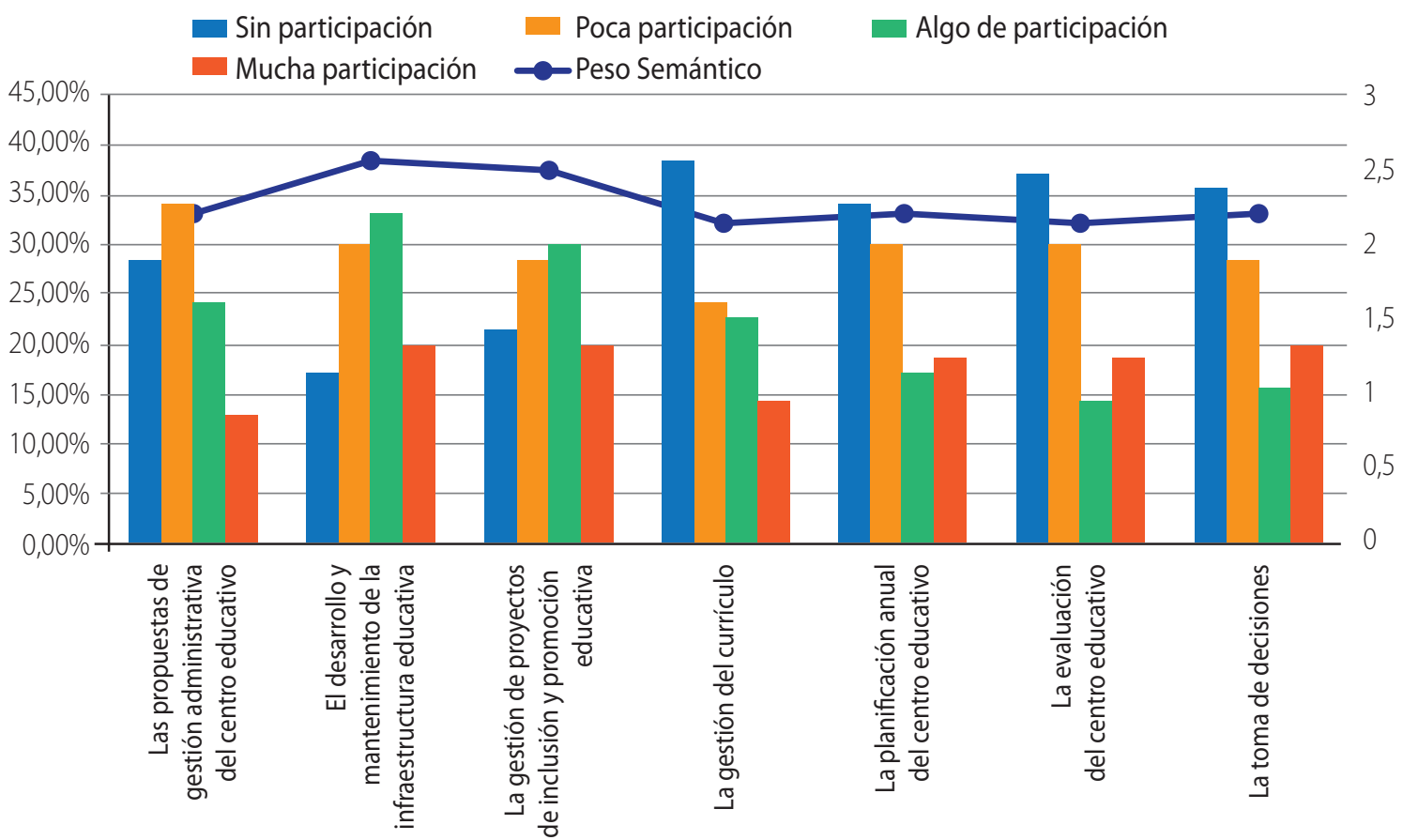

Fuente: información suministrada por los participantes del estudio "Construcción de indicadores para la gestión administrativa y curricular de centros educativos para el mejoramiento del desempeño educativo", en marzo de 2019.

De lo anterior se desprende el desafío de cómo llevar a cabo procesos de articulación y vinculación con la comunidad, más allá del ámbito formal y de los espacios institucionalizados.

Pareciera que en los contextos educativos prima una forma de participación que podríamos llamar estructural-administrativa, y deriva de los espacios formales de coordinación institucional.

Se podría pensar en trascender a una segunda modalidad de participación, que es la contributiva: se da cuando una determina comunidad o sus actores participan creando procesos que generen las condiciones para la equidad y la inclusión social.

\section{SÍNTESIS Y REFLEXIONES FINALES}

La gestión educativa, tanto de directores como de supervisores, es continua para la toma de decisiones, sea en materia de planificación, evaluación, organización y puesta en práctica de procesos. Por ende, resulta fundamental que la toma decisiones de gestión sea informada, con datos, para ofrecer respuesta a los problemas del contexto de manera pertinente, en consecuencia, el papel de los indicadores educativos, como herramientas orientadas hacia la eficiencia. (Ramírez y Lorenzo, 2009).

El contexto cambiante socioeducativo, amerita contar con instrumentos y herramientas para la evaluación y el seguimiento que permitan calidad del servicio y el cumplimiento de la política educativa y todas las 
acciones derivadas de esta. Desde tal perspectiva, el proyecto de investigación pretende romper con la gestión tradicional y avanzar en la generación de indicadores prácticos para la gestión educativa.

\section{Dimensión comunitaria}

Los indicadores de carácter comunitario desde la gestión y a partir de la experiencia de investigación tienen que construirse de forma participativa y con un diagnóstico socioeducativo, con el fin de contemplar acciones vinculantes, reconocimiento de las demandas de la comunidad y puesta en práctica de mecanismos de trabajo colaborativo centro educativo-comunidad.

Los indicadores son, principalmente, información para dar seguimiento y flexibilizar acciones de los distintos procesos establecidos para el cumplimiento de los objetivos institucionales y nacionales, en el ámbito comunitario se convierten en mecanismos de monitoreo y evaluación para la mejora. (Valle y Rivera, 2008).

En términos generales, la planificación, organización y proyección de la institución educativa debe nutrirse de la presencia y vinculación activa de los distintos actores de la comunidad, con indicadores claves para una correspondencia efectiva realidad-educación.

Por otro lado, en materia de las Juntas de Educación y Patronato Escolar, desde la investigación se evidencian tensiones entre la comunidad y la estructura del sistema, además de falencias de los miembros que integran dichas instancias. En tal sentido, el papel del liderazgo directivo para fortalecer los organismos de apoyo y canalizar las demandas y visiones ante instancias del sistema, direcciones regionales del MEP, municipalidades y otras demandas, se convierte en un factor determinante. Además de promover un proceso de formación permanente a los miembros de estos espacios para que sus perfiles sean más pertinentes.

En síntesis, el liderazgo, la mediación y el acompañamiento es clave por parte de las personas directivas, pero no resulta suficiente, se requieren indicadores de desempeño y resultados para evaluar la efectividad de Juntas de Educación y el Patronato Escolar. Como resultado el monitoreo implica actividades de seguimiento de indicadores que faciliten evaluar avances y regresiones en las actividades que hacen parte del sistema y proyecto (Loaiza, Reyes, Carvajal, 2011).

Asimismo, en materia de fortalecer la comunidad resulta indispensable que los directivos escolares generen espacios de consulta, rendición de cuentas y diálogo. Es importante que el área normativa se aborde desde una óptica de gestión efectiva y democrática, de carácter representativo. Para lograr tal propósito, son necesarios los indicadores de seguimiento a procesos de coordinación y rendición de cuentas, junto con los mecanismos de comunicación.

\section{La ruta a generar indicadores}

Es una necesidad trabajar en construir indicadores que generen información efectiva en la gestión en sus distintos niveles, orientado a incentivar autonomía para la resolución de problemas y respuestas adecuadas al contexto, donde los directivos escolares establezcan mecanismos de control y seguimiento para el ámbito comunitario.

Sin embargo, desde el nivel central, se requiere sobrepasar los indicadores con foco en los resultados y apostar a la construcción de indicadores contextualizados, de seguimiento más acordes a la realidad socioeducativa.

Los indicadores se convierten en mecanismos para favorecer la política educativa, curricular a nivel nacional y regional, con gestores que posean conocimientos y medios para alinear su gestión con los postulados de desarrollo. 
Los indicadores educativos tienen que contextualizarse, de acuerdo con las características sociales, económicas, culturales de las instituciones educativas. La persona directora debe tener la posibilidad de adecuarlos a las circunstancias del espacio educativo, reflejar sus necesidades y las características de cada ámbito comunitario.

Al fin de cuentas, el reto para las personas directivas es convertir al centro educativo en un espacio de confluencia y articulación de líderes comunales, instituciones públicas y privadas, con un plan anual y quinquenal que incluya indicadores para desarrollo del proyecto educativo.

En general el reto es, acompañar y apoyar desde la Universidad la formación y capacitación de las personas gestoras de la educación y los distintos actores del sistema educativo para favorecer la construcción de centros educativos unidos al tejido comunitario.

\section{REFERENCIAS}

Abarca, A., Alpízar, F., Sibaja, G. \& Rojas, C. (2013). Técnicas cualitativas de investigación. San José, Costa Rica: Editorial de la Universidad de Costa Rica.

Antúnez, Serafín. (1998). Claves para la organización de centros escolares (IV). Horsori. Recuperado de http://www.terras.edu.ar/aula/cursos/8/biblio/8ANTUNEZ-Serafin-CAP8-Innovacion-y-Cambio-enlos-Centros-Escolares.pdf

Aravena-Castillo, F. (2020). Liderando establecimientos escolares en tiempos de pandemia: algunas certezas entre las incertezas. Innovaciones Educativas, 22(33):6-8. https://doi.org/10.22458/ie.v22i33.3344

Bellido, A. C., J. Díaz Donado, F. Morales Ríos \& Pino de Ochoa, L. (2009). Gestión y supervisión en el centro de educación básica (Vol. 36). San José Costa Rica: Coordinación Educativa y Cultural Centroamericana. Recuperado a partir de http://www.ceducar.info/ceducar/recursos/biblioteca-virtual/volumen36. pdf

Bernal, C. (2010). Metodología de la Investigación administración, economía, humanidades y ciencias sociales. Bogotá, Colombia: Pearson Educación.

Casas, J., Repullo, J.R. y Donado, J. (2003). La encuesta como técnica de investigación. Elaboración de cuestionarios y tratamiento estadístico de los datos (I) Atención primaria: Publicación oficial de la Sociedad Española de Familia y Comunitaria, ISSN 0212-6567, 31(9):592-600.

Casassus J. (1999). Marcos conceptuales para el análisis de los cambios en la gestión de los sistemas educativos. En La gestión: en busca del sujeto. Santiago de Chile. UNESCO. Recuperado a partir de http:// unesdoc.unesco.org/images/0011/001176/117612so.pdf

Consejo Superior de Educación (2008). El centro educativo de calidad como eje de la educación. San José, Costa Rica.

Consejo Superior de Educación (2017). La persona: centro del proceso educativo y sujeto transformador de la sociedad. San José, Costa Rica.

Contreras, P. (2019). Incidencia De la Gestión Escolar y Liderazgo en las Instituciones Educativas: Perspectiva de Análisis. Revista Daena (International Journal of Good Conscience), 14(1):52-68

Elboj, C.;Puigdellívol, I.; Soler, M.; Valls, R. (2002). Comunidades de aprendizaje. Transformar la educación. Barcelona, Graó.

García, B. (2010). Modelos teóricos e indicadores de evaluación educativa. Revista Electrónica de Educación Sinéctica, (35):1-17. Recuperado el 25 de marzo de 2021, de http://www.scielo.org.mx/scielo. php?script=sci_arttext\&pid=S1665-109X2010000200005\&lng=es\&tlng=es

González, Tomás Díez. 2004. "Política del Ministerio de Educación y Ciencia En Temas de Educación de Adultos (1970-1990)." Pp. 81-112 en Política de educación de adultos. Universidad de Santiago de Compostela. 
Hernández, R., Fernández, C. y Baptista, M. (2014). Metodología de la investigación. México DF: McGraw-Hill.

Jiménez, A. B. (2011). Escuelas rurales y educación democrática. La oportunidad de la participación comunitaria. Revista electrónica interuniversitaria de formación del profesorado,14(2):105-114.

Krause, J. M. (2001). Hacia una redefinición del concepto de comunidad. Revista de Psicología de la Universidad de Chile, 10(2):49-60.

Krichesky, M. (2006). Escuela y comunidad, desafíos para la inclusión educativa. Buenos Aires: Ministerio de educación, Ciencia y Tecnología de la Nación.

Loaiza, W., Reyes, A., Carvajar, Y. (2011) Modelo para el monitoreo y seguimiento de indicadores de sostenebilidad del recurso hídrico en el sector agrícola. Revista Colombiana de Geografía, 20(2):77-89, julio-diciembre del ISSN: 0121-215X |.

López, P., Fachelli, S. (2015). Metodología de la investigación social cuantitativa. Barcelona, Universidad Autónoma de Barcelona.

Márquez, A. (2010). Sistemas De Indicadores Educativos: Su Utilidad en El Análisis De Los Problemas Educativos. Revista Electrónica de Educación Sinéctica, (35):2-25.

Mingorance, P. \& Estebaranz, A. (2009). Construyendo la comunidad que aprende: la vinculación efectiva entre la escuela y la comunidad. Revista Fuentes (9):179-199. Recuperado de https://ojs.publius.us.es/ ojs/index.php/fuentes/article/view/2546

Morduchowicz, A. (2006). Los indicadores educativos y las dimensiones que los integran. Buenos Aires. IIPE-UNESCO

Muñoz, R. (2014). El Derecho a La Educación Y La Construcción De Indicadores Educativos Con La Participación De Las Escuelas. Revista Electrónica de Educación Sinéctica, (43):1-19.

Murillo, J. (2006). Una dirección escolar para el cambio: del liderazgo transformacional al liderazgo distribuido. REICE, Revista Iberoamericana sobre Calidad, Eficacia y Cambio en Educación, 4(4e).

Palomar, J., \& Flecha García, R.(2010). Comunidades de Aprendizaje: un proyecto de transformación social y educativa. Revista Interuniversitaria de Formación del Profesorado, 24(1). Recuperado de http://www. redalyc.org/html/274/27419180002/

Pincheira, L. (2010). La participación educativa de padre, madre y/o apoderado en el centro educativo mito o realidad. REXE. Revista de Estudios y Experiencias en Educación, 9(17):107-114.[Recuperado en: https://www.redalyc.org/articulo.oa?id=243116388006

Ramírez, C., García, E., Cruel, J. (2017). Gestión educativa y desarrollo social. En: Dominio de las Ciencias, 3,(Extra 1): 378-390

Ramírez, M. \& Quesada, J. (2019). Repensando los indicadores educativos: la gestión educativa, curricular y de vinculación con la comunidad. Revista Innovaciones Educativas, 21(30):37-47. Recuperado de https://revistas.uned.ac.cr/index.php/innovaciones/article/view/2483/3153

Rivera, A., Rojas, L., Ramírez, F., Álvarez, T. (2005). La comunicación como herramienta de gestión organizacional. Negotium, 1(2):32-48 Recuperado en: https://www.redalyc.org/articulo.oa?id=78212103

Sánchez, C. (2018). La inclusión educativa como proceso en contextos socioeducativos. Madrid: UNED.

Taccari, D. (2010). Mecanismos De Monitoreo De Los Compromisos en Educación en América Latina: Sistemas Regionales De Indicadores Educativos. Revista Electrónica de Educación Sinéctica, (35):2-25.

Torres, A. (2002). Vínculos comunitarios y reconstrucción social. Bogotá: Universidad Pedagógica Nacional. Revista Colombiana de Educación, (43):43-68.

UNESCO (2011). Manual de gestión para directores de instituciones educativas. Lima: UNESCO

Valle, O., Rivera, O. (2008). Monitoreo e indicadores. Andalucía: OEI. 